\title{
CONTRIBUIÇÕES DA LUDICIDADE PARA O ESTUDANTE NO PROCESSO DE ENSINO-APRENDIZAGEM DA MATEMÁTICA
}

\author{
Maria Luiza Figueredo de Araújo ${ }^{1}$ \\ Marlucia da Silva Ribeiro ${ }^{2}$
}

\begin{abstract}
RESUMO
O objetivo desse estudo é analisar as contribuições da ludicidade no processo de ensinoaprendizagem da Matemática. Têm-se ainda os específicos: descrever os aspectos históricos do ensino da Matemática; compreender a importância do lúdico, da ludicidade e dos jogos no processo de ensino-aprendizagem dos educandos. A partir desse levantamento bibliográfico, conclui-se que muitas são as contribuições das atividades lúdicas no processo de ensinoaprendizagem da Matemática. Para isso, os jogos, os brinquedos e os jogos devem ser bem planejados, para que haja um sentido e para que o aluno possa sempre fazer um link e dar um significado, ligando a atividade com objeto em estudo na área desejada. Portanto, essas podem e devem ser utilizados para introduzir, amadurecer conteúdos e preparar o educando para aprofundar os itens já trabalhados, além de conseguirem estabelecer relações entre teoria e a prática. Porém, necessário se faz ter cautela na escolha desses materiais e/ou metodologia para aplicá-los, para que assim, assumam o seu caráter lúdico e fim didático.
\end{abstract}

Palavras- chaves: Ludicidade. Ensino-aprendizagem. Matemática

\begin{abstract}
Or objective desse study and analyze the contributions of the student for study or not process of teaching-learning mathematics. These are also specific: to uncover the historical aspects of mathematics; compreender a playful importance, gives ludicidade two jogos no process of ensino-aprendizagem two learners. From this bibliographic survey, it is concluded that many contributions are made to the leisure activities, not to the process of teaching-learning mathematics. For this, the jogos, the jokes, and the joys must be planned, so that there is a sense in which all or some of the objects will always link and give meaning, linking to the object in the desired area. Therefore, these can also be used to introduce, love content and prepare or educate to improve the work, in addition to being able to establish relationships between theory and practice. Porém, necessário is faz ter cautela na escolha desses materiais and / or methodology to apply them, so that assim, assumam or seu caráter lúdico and fim didactic.
\end{abstract}

Keywords: Playfulness. Teaching-learning. Math

\section{INTRODUÇÃO}

O ensino da Matemática ao longo da história assumiu uma conotação

\footnotetext{
${ }^{1}$ Mestra em Ciências da Educação pela Faculdade Interamericana de Ciências Sociais (FICS). Licenciada em Matemática pela Faculdade Jorge Amado. Especialista em Metodologia do Ensino Superior pelo Centro Universitário da Bahia (FIB). Especialista em Metodologia do Ensino da Matemática pelo Instituto Superior de Educação Afonso Cláudio (ISEAC). Docente pela Secretaria de Educação de Salvador - Ba. E-mail: luizafigueredoaraujo@hotmail.com

${ }^{2}$ Mestra em Ciências da Educação pela Faculdade Interamericana de Ciências Sociais (FICS). Licenciada em História pela Universidade Católica de Salvador (UCSAL). Especialista em Metodologia de Pesquisa e Extensão pela Universidade do Estado da Bahia (UNEB). Especialista em Avaliação pela Universidade do Estado da Bahia (UNEB). Funcionária Pública do Estado da Bahia e da Prefeitura de Salvador. E-mail:ribeiromarlucia89@gmail.com
} 
pejorativa, sendo encarada, para a maioria dos alunos e dos pais, como um "monstro". Isso pode ser identificado e confirmado pelos altos índices de reprovação e nível insuficiente apresentados pelo Sistema de Avaliação da Educação Básica (2017), sendo que no Ensino Médio, sete em cada dez alunos apresentam dificuldades nessa área do conhecimento. Em outras palavras, $89 \%$ chegam ao final do ensino médio sem dominar o mínimo das habilidades e competências em matemática (BRASIL, 2017).

Cabe ressaltar, que essa área do conhecimento é de extrema importância para que o sujeito compreenda como funciona as relações, que exigem conhecimentos matemáticos, em seu cotidiano. Parte da sociedade, acredita que esse "insucesso" esteja associado a forma tradicional que a matemática é apresentada pela maioria dos professores, sendo selecionados e aplicados conteúdos sem contextualização, de maneira repetitiva e mecânica.

$\mathrm{Na}$ tentativa de apresentar uma nova configuração no ensino da Matemática, têm-se estudos que defendem a relação entre a ludicidade, o lúdico e os jogos, sendo aplicados no processo de ensino-aprendizagem da matemática. Essa perspectiva de estudo proporciona ao educando e ao educador a possibilidade de incorporar novos instrumentos e práticas pedagógicas significativas. Neste cenário, os jogos aparecem como um dos elementos favoráveis pela incansável busca de qualidade na aprendizagem.

Nesse contexto, levanta-se a seguinte questão: quais são as contribuições da ludicidade para o estudante no processo de ensinoaprendizagem da Matemática?

O objetivo geral desse estudo é analisar as contribuições da ludicidade para o estudante no processo de ensino-aprendizagem da Matemática. Têm-se ainda os específicos: descrever os aspectos históricos do ensino da Matemática; compreender a importância do lúdico, da ludicidade e dos jogos no processo de ensino-aprendizagem dos educandos.

A importância dessa pesquisa, dialoga com as experiências profissionais, as quais observam-se que existe uma distância entre o que e como é apresentado no ensino da Matemática, sendo exposta, na maioria das vezes, de forma tradicional, apenas com atividades e práticas relacionadas aos livros didáticos. Assim, confirma-se a rejeição pelos conteúdos matemáticos 
por parte dos alunos, pois os mesmos a reconhecem como um "bicho de sete cabeças", por não atenderem suas necessidades.

Para a elaboração desse estudo, que foi de abordagem qualitativa e natureza bibliográfica, utilizou-se de referência de autores consagrados na área: Luckesi (2002), Huizinga (2005), Lavroski e Venditti (2010) que dissertam sobre a importância do lúdico e da ludicidade no processo de ensino e aprendizagem. Jesus (2010), Friedmann (1996), Bougére (2001), Kishimoto $(1998,2001,2008)$, Antunes $(2001,2006)$ que tratam do jogo, da brincadeira e do briquedo e de que maneira esses influenciam para o processo de ensinoaprendizagem se torne significativo. Grado (1995), Moura (1996) que trazem o jogo e suas possibilidades metodológicas no processo ensino-aprendizagem da matemática. Dentre outros estudiosos da área.

Além dessa parte introdutória, esse artigo divide-se ainda em mais quatro seções: o breve histórico do ensino da Matemática, o Lúdico da Ludicidade no processo de ensino-aprendizagem, e das contribuições da ludicidade nesse processo na Matemática. E ainda as considerações finais.

\section{BREVE HISTÓRICO DO ENSINO DA MATEMÁTICA}

A história do surgimento da Matemática tem um papel importante no ensino, não dá para desvincular um do outro. Essa área do conhecimento deu origem ao ensino como mediadora, ou seja, provedora de recursos do processo de ensino-aprendizagem, possibilitando uma reflexão positiva na forma de como o aluno concebe as operações matemáticas.

Segundo Crepaldi (2005) a Matemática tem origem desde a Idade Média, onde o homem já utilizava símbolos para estabelecerem comunicação. Ela foi criada, justamente para atender as necessidades da época, no que diz respeito aos problemas que eram de ordem prática, sendo evidenciada em transações como na divisão de terras; na coleta e divisão dos animais e dos alimentos; na tentativa de entender os fenômenos da natureza; dentre outras ações.

Desde então, a Matemática acompanha a evolução do homem. Afonso (2002) pontua que foram vários os povos que contribuíram para o avanço dela, dentre os povos, os primeiros foram os egípcios que contribuíram ao 
apresentarem o primeiro sistema de numeração e baseados nas quantidades de objetos, sendo esses materializados em diversos símbolos. Nesse momento, observa-se um avanço notório nas atividades relacionadas ao comércio e das indústrias. Outros pontos de excelência dessa época foram as construções das pirâmides e templos egípcios; a criação do calendário com 365 dias e o relógio, que tinha como base o sol; os algarismos romanos; e ainda os sistemas de contagem, que utilizavam em sua essência as pedras, ábaco e as mãos.

A História da Matemática começa a ser desenhada para o mundo no século XVIII. Nome como o do francês Alexis Claude Clairaut (1713-1765) defendia, em sua obra Eléments de Geometrie, a importância do ensino de geometria, levando em consideração os aspectos históricos, pois para ele, a humanidade aprende através das leis e conceitos matemáticos. No século $X X$, tem-se o matemático alemão Felix Klein, autor da obra Elementary Mathematics from an Advanced Standpoint, também contempla a História da Matemática, agora confrontando o método de desenvolvimento da matemática, defendendo que essa deve ser apresentada de maneira pedagógica aos sujeitos. Outro nome de destaque é o de Poincaré que traz à tona a Matemática como recurso pedagógico e a necessidade de apresentar procedimentos que estimulem o aluno a desenvolver seu pensamento crítico (MIGUEL e MIORIN, 2011).

No Brasil, segundo Brito (2007), o ensino da Matemática enquanto disciplina, contempla os seguintes períodos: o primeiro foi o período jesuítico, durante a colonização, sendo ofertado pela primeira vez no curso secundário de Artes e Filosofia no Colégio de Salvador, sendo ofertado apenas para a elite burguesa da época. Cabe ressaltar que o principal documento desse período foi Ratio Studiorum, primeiro plano organizacional com base nos princípios católicos.

Dando um salto quantitativo, o segundo momento ocorreu em 1810, quando ocorre a institucionalização do Ensino da Matemática, agora no ensino Superior no Brasil, sendo de responsabilidade da Academia Real Militar na Corte do Rio de Janeiro. Nesse curso, os estudantes tratavam de questões relacionadas as Aritmética, Álgebra, Geometria Trigonometria, Desenho, Cálculo Diferencial e Integral, Geometria Descritiva, Mecânica. Em, 1896 até 
1929, o ensino da matemática era dado exclusivamente nos cursos de engenharia. A partir de 1930, em São Paulo com o surgimento da USP, foi considerada como uma das pioneiras em estudos das Matemáticas no Brasil (BRITO, 2007). Em 1950, com o primeiro Colóquio Brasileiro de Matemática, tem-se a terceira fase do ensino da Matemática, contando com várias gerações de matemáticos, onde ocorreu o aumento considerável na demanda de oferta de cursos de graduação em matemática em quase todo o país (BRITO, 2007).

Entre os anos 60 e 70 aconteceu no Brasil, mais precisamente no estado de São Paulo, um movimento conhecido como MMM (Movimento da Matemática Moderna), com o objetivo de provocar uma intensa e diversificada mobilização acerca de mudanças para renovação do ensino da matemática. Esse movimento teve um impacto direto nas práticas docentes de professores e no currículo trabalhado nas escolas secundarias dessa época. Segundo Búrigo (2006, p. 36), "as discussões foram concentradas em São Paulo, em que a difusão das propostas de renovação foram assumidas pelo GEEM (Grupo de Estudos do Ensino da Matemática), fundado em outubro de 1961".

Sabe-se que as discussões acerca das potencialidades pedagógicas da história no ensino de Matemática acontecerão desde o século XVII, porém, no início do século XIX, é que essas discussões ganharão ainda mais força, sendo pautas de congressos internacionais sobre o ensino de Matemática. Isso é evidenciado por D'Ambrosio, (2011, p. 61) ao colocar que:

\footnotetext{
O século XIX pode ser visto como o século da consolidação da Matemática Ocidental, desenvolvida desde a Antiguidade. É, por muitos, considerado $O$ século de Ouro da Matemática. Os padrões de rigor que prevalecem na matemática atual se consolidaram nesse século.
}

Desta forma, percebe-se que a história da matemática, se bem interpretada, poderá ser vista como inspiração, para o processo de ensinoaprendizagem, pois utiliza representações que já visavam a mobilização de conhecimentos que levem ao sujeito a despertar o senso crítico. A integração da história da matemática com o ensino da matemática tem se destacado em três aspectos considerados relevantes. 
diferenciada da matemática, que passa a ser vista como atividade intelectual e humanizadora, ao invés de um corpo de conhecimento dado ou um conjunto de técnicas de resolução de problemas matemáticos.

O segundo aspecto está relacionado à percepção do conhecimento matemático. A articulação de tópicos de história no ensino de matemática tem possibilitado a reorientação da visão do que são os objetos da matemática, pois o estudo do processo histórico conduz a uma linha interpretativa diferenciada, propiciando a abordagem do mesmo objeto matemático por outra perspectiva e, assim, contribuindo para sua melhor compreensão.

O terceiro aspecto a ser considerado é a interdisciplinaridade, na qual o processo histórico tem se mostrado eficaz ao abordar o desenvolvimento dos conceitos matemáticos, na medida em que os insere num contexto particular e estabelece relações com outras áreas do conhecimento científico, tecnológico e social. (SAITO; DIAS, 2009, p 92).

Nesse sentido, esses aspectos tem sido veículos de grandes valores informativos para o ensino da matemática, sendo instrumentos de resgate cultural da época. Desta forma, percebe-se que esse resgate quando aliado aos recursos didáticos e metodológicos, tem muito a contribuir com o processo de ensino-aprendizagem da matemática. Isso, em certa medida, permite ao professor novas reflexões acerca dos fundamentos do ensino da matemática, de forma que possa relacionar a matemática a diferentes campos do conhecimento fortalecendo assim sua prática como educador

Com isso, fica claro que a história da matemática traz a abordagem dos problemas de forma contextualizada, mostrando na íntegra como surgiram e como se desenvolveram, abrindo um leque de discussões em diferentes áreas do conhecimento, promovendo o exercício da interdisciplinaridade.

Como toda área do conhecimento, pesquisas e estudos em história da matemática dependem de especialistas, pois diferentemente do que pensa o senso comum, não basta juntarmos história e matemática para que o resultado final seja, provavelmente, história da matemática, visto que a soma de duas coisas, neste caso, resulta numa terceira com características próprias, diferente daquela que lhe deram origem. (SAITO; DIAS, 2009, p. 91).

Desta forma, percebe-se a importância de se estabelecer diálogo entre os aspectos do cotidiano da escola e os aspectos científicos da matemática, de forma que esses aspectos sejam priorizados nas atividades selecionadas para trabalhar em sala de aula.

Como viu-se a história no ensino da matemática vai muito além do que apresentar informações mecânicas, pois para o ensino significativo são necessários levar em considerações aspectos históricos e socioculturais nos 
quais os estudantes estão inseridos, onde explicam sua realidade.

\section{O LÚDICO E A LUDICIDADE NO PROCESSO DE ENSINO E APRENDIZAGEM}

A escola é um dos principais espaços em que as crianças são expostas as situações lúdicas. É importante ressaltar que esse público não pode ser privado de conhecer essa cultura, que por sua vez, proporciona inúmeros momentos de lazer e acima de tudo aprendizagem. Os momentos lúdicos se tornam em essência a materialização da diversão e entretenimento, seja de maneira coletiva ou individual.

Antes de iniciar sua vida educacional, e durante o seu processo de formação, a criança constrói parte do seu conhecimento através do lúdico, ou seja, de situações livres ou condicionadas que o elevam ao estado de prazer e fruição. Nesses momentos, ela é exposta a situações reais, mas por meio do brincar. E é justamente na escola, que agora, essas circunstâncias ganharão intencionalidade. Não cabendo mais a ideia de entreter-se por simples divertimento (LUCKESI, 1998).

Etimologicamente, a palavra ludicidade é originária do latim ludus que quer dizer jogo, divertimento, circo e também possui o significado de escola onde existiam muitos exercícios (militar, de gladiadores, primária, de ler e escrever). Isso é evidente ao colocar que o brincar faz parte do processo de formação do ser humano e sempre esteve presente desde os tempos mais remotos, adaptando-se a cada época a contexto histórico. É um ato intrínseco do ser humano. Portanto, era utilizado para diversos fins (LUCKESI, 1998).

Retomando brevemente a história, Queiroz (2009) pontua que Inicialmente quem se interessou por estudar os benefícios que o lúdico trazia ao desenvolvimento humano foi Platão apresentando, na temática dos jogos, a sua importância na aprendizagem para área das ciências exatas. Tanto na Grécia como no Egito as famílias costumavam brincar ensinando os ofícios para seus filhos. Cabe ressaltar ainda, que nesta época ainda não se falava em infância. As atividades lúdicas praticadas eram meramente para ensinar as crianças a se portarem como adultos, reproduzindo suas tarefas.

Ao longo da história, as crianças, por muito tempo, foram tratadas e 
classificadas como adultos, sendo negadas suas infâncias. Os jogos e brincadeiras, nesse período, tinham o objetivo de despertá-las para os papeis sociais, as quais ocupariam. Essa perspectiva começa a modificar-se com os modelos da educação cristã. Pontualmente, a partir do Renascimento, os jogos, as brincadeiras e o brinquedo ganham novos espaços, agora na sala de aula, principalmente nos colégios jesuítas (KISHIMOTO, 1998).

Os jogos são frutos, principalmente, das civilizações antigas, como da Grécia e Roma, pois essas nações acreditavam no poder de influência que eles exerciam para o desenvolvimento na formação de sujeitos forte e determinados. Sobre isso, Jesus (2010, p. 03) acrescenta que "em Antenas e em Roma, já existiam brinquedos destinados a facilitar a aprendizagem de movimentos, ou para ensinar as letras como a marcha, brincadeiras com arcos, jogos com ossinhos".

A partir do século XVIII com a proposta de Froebel (1782-1852 apud JESUS, 2010, p. 06) "acreditava que brincar livre e o uso de jogos para educar crianças na pré-escola poderiam ser introduzidos no contexto infantil, considerando que a criança desperta as habilidades mediante o estimulo". Essa postura ganha fôlego, sendo utilizada na maioria das escolas da época. Ao trazer à tona as brincadeiras, os jogos e o brinquedo em questão, por muitas vezes, os classificamos como se fossem a mesma ação/objeto, sendo que ambos possuem características e finalidades distintas.

No que diz respeito às diferenças, Kishimoto (1998, p. 08) coloca que "[...] o brinquedo não pode ser isolado da sociedade que o criou e reveste-se de elementos culturais e tecnológicos do contexto histórico cultural". Nesse sentido, o brinquedo será entendido como um objeto, ou seja, como uma espécie de suporte para a brincadeira. Nessa perspectiva, entende-se que esses objetos fazem parte, em certa medida, de nossa cultura. Esses ainda podem ser considerados como representações simbólicas, que são materializadas de diferentes formas e imagens, sendo sempre atrelados a brincadeira, está como a descrição de uma conduta estruturada.

O brinquedo, enquanto instrumento pedagógico, é pontuado por Brougère (2001, p. 48) como " valor lúdico que reforça a eficácia simbólica do brinquedo. É isso, que faz a especificidade desse em relação aos suportes culturais". Ao trabalhar com o brinquedo em sala de aula, deve-se ser levado 
em consideração alguns aspectos como: o aspecto material do brinquedo, 0 (forma, tamanho, cor, odor, ruído, sons e outras); a representação, ou seja, o brinquedo tem o poder de expressar realidades, universos e tempos diversos.

Ainda sobre o brinquedo, Kishimoto (2009) o classifica como um instrumento que estimula a representação dos aspectos da realidade:

O brinquedo coloca a criança na presença de reproduções: tudo o que existe no cotidiano, a natureza e as construções humanas. Podese dizer que um dos objetivos do brinquedo é dar à criança um substituto dos objetos reais, para que possa manipulá-los (KISHIMOTO, 2009, p. 18).

Nessa perspectiva, esse objeto tem o poder de influenciar no imaginário da criança, pois, com ele, a criança pode criar e recriar possibilidades de representações.

Ainda nessa discussão, Vygotsky (1998, p. apud BOUGÈRE, 2001, p. 50) afirma: "a essência do brinquedo é a criação de uma nova relação entre o campo do significado e o campo da percepção visual, ou seja, entre situações no pensamento e situações reais". Assim, o brinquedo está inserido de maneira direta nas brincadeiras, pois devem ser colocados como algo de diversão.

Esse instrumento pode tomar diferentes representações e proporções. Cabe ressaltar que qualquer objeto pode assumir uma forma lúdica nas mãos das crianças, ou seja, elas fingem, imaginam, simulam com "a coisa" que detém nas mãos algo de seu repertório (sua imaginação), sendo esses atos uma externação de suas emoções e constituição de mundo a seu jeito. O que é algo importante e crucial para criança, que está iniciando uma vida e adquirindo experiência, bagagem, autonomia e subsidio para seu futuro (JESUS, 2010)

No que diz respeito às brincadeiras, essas podem ser classificadas como situações representadas pelas crianças, que, por vezes, podem ser uma materialização de "cenas" que foram presenciadas e assimiladas no inconsciente da criança, como por exemplo através do desenho, da novela, de uma experiência familiar ou qualquer outra situação que possa inspirá-las. Sobre as influências sofridas pelo público infantil, Brougère (2001) acrescenta que a mesma é possível pela influência direta que a televisão, por exemplo, exerce sobre as crianças. Ainda sobre as brincadeiras, Kishimoto (1997) 
apresenta de maneira clara as classificações das brincadeiras:

Brincadeiras tradicionais infantil, filiadas ao folclore incorporam a mentalidade popular, expressando-se, sobretudo, pela oralidade. [...] A tradicionalidade e universalidade das brincadeiras assentam-se no fato de povos distintos e antigos, como os da Grécia e do Oriente, brincaram de amarelinha, empinar papagaios, jogar pedrinhas [...]

Brincadeiras de faz-de-conta também conhecida como simbólica de representação de papéis ou sócio-dramáticas, é a que deixa mais evidente a presença da situação imaginaria. Ela surge com 0 aparecimento da representação e da linguagem em torno do 2-3 anos $[\ldots]$

Brincadeiras de construção, os jogos de construção são considerados de grande importância por enriquecer a experiência sensorial, estimular a criatividade e desenvolver habilidades da criança[...]. (KISHIMOTO, 2012, p. 38-40)

Nesse sentido, as brincadeiras podem expressar diferentes contextos, podendo exprimir ainda a cultura, as heranças históricas e experiências vivenciadas, uma vez que podem se materializar no folclore, resgatando ainda povos e culturas passadas. Como também é responsável pela construção simbólica dos papeis sociais assumidos.

Já o jogo, em linhas gerais, é toda atividade que dispõe de regras, sendo estruturados ou semiestruturados, praticadas com fins recreativos e, em alguns casos, como instrumento educacional. Partindo das definições de jogo apresentada pelo dicionário Houaiss, (2003 p.400) tem-se;

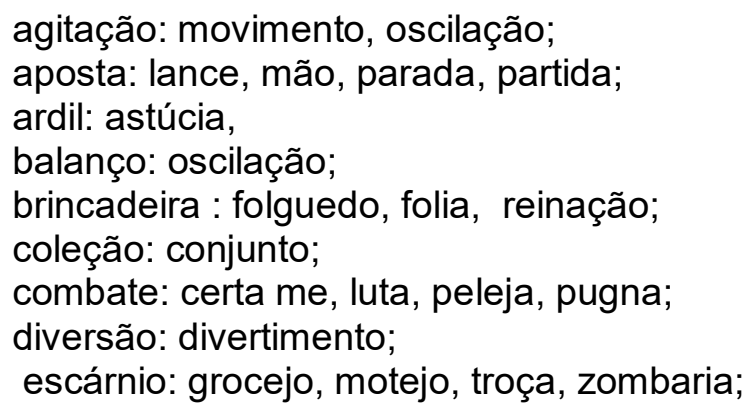

Nas civilizações antiguíssimas, como exemplo a Grécia, no século XVI, os jogos ganhavam destaques, pois, eram realizadas por puro prazer, seu objetivo principal era a socialização. Quando o objetivo de qualquer tipo de jogo relacionava-se a guerra, o mesmo era negado. Uma das características do jogo na Idade Média era a sua seriedade, fator favorável quando existia algum tipo de discordância entre os povos de diferentes civilizações. 
Ao longo dos anos, essa visão foi substituída pelos jogos enquanto práticas esportivas e passaram a ter um caráter competitivo tornando-se um instrumento de poder.

\begin{abstract}
Ao longo da história o ser humano constituiu seus conceitos matemáticos por meio da utilização de objetos concretos (pedra, sementes etc.) para contar seus pertences, e limitar seu território e construir objetos de utilização pessoal. Será que o educador chegou para homem primitivo dizendo: "hoje vamos aprender a contar"? É claro que não. Os conceitos matemáticos foram sendo construído gradativamente ate chegarmos ao presente avanço tecnológico (ARANÃO, 1996, p. 27).
\end{abstract}

Houve também quem considerasse o jogo como mundano. A igreja, na Idade Média, via o lúdico como algo profano e consequentemente a educação saiu perdendo, pois a igreja era quem ditava as regras exercendo sua influência na formação dos princípios morais, políticos e constitucionais da sociedade.

\begin{abstract}
Embora seja grande a produção intelectual na Renascença, não foi capaz de mudar significativamente as concepções em relação às crianças, que continuam desconhecidas em sua natureza singular, até que pensadores como Erasmo; Vives; Rabelais; Montaigne; Comênius e, posteriormente, Rosseau e Pestalozzi; realizaram estudos sistemáticos sobre educação, chamando a atenção para a 'responsabilidade social' da ciência, o reconhecimento do desenvolvimento infantil e os aspectos psicológicos no ensino. (QUEIROZ, 2009, p. 19)
\end{abstract}

Com a Revolução industrial, com o disparo do pensamento capitalista, as crianças sofreram com as influências na educação. Sua permanência na escola foi reduzida para que pudessem trabalhar nas fabricas. As ditas escolas não ofereciam uma educação de qualidade, o ambiente escolar era degradante sem nenhuma infraestrutura, as crianças iam apenas para receber um atestado de frequência escolar.

No Brasil, os jogos têm raízes folclóricas e influência de pelo menos três grupos de etnias, os negros vindos da África para substituir a mão de obra indígena, que já habitavam aqui, e os brancos formados pelos portugueses (europeus), responsáveis pela colonização. Assim, o jogo está impregnado de costumes singulares e características originais. Outra influência que é pertinente citar é a intensificação do movimento de imigração de origem mediterrânea e germânica (portugueses, espanhóis, italianos, alemães e outros). Essa "mistura" de civilizações acentuou as influências de seus 
folclores, de modo que durante o processo de miscigenação, o folclore brasileiro recebeu novas características que também impregnaram os jogos e brincadeiras na história cultural do nosso país (ARANÃO, 1996).

Nesse sentido, o jogo pode ser considerado como atividade livre e voluntária, proporcionando ao sujeito alegria e diversão. Para tanto, ao jogar, as crianças passam a lidar com as regras que, em certa medida, permitem a compreensão do conjunto de regras que são inseridas no contexto social. É através das situações de jogos que as crianças criam estratégias e levantam hipóteses com o intuito de resolver a situação problema. Assim, a criança passa a ter algo que desejava na imaginação, concretizando o abstrato, resultando um processo de construção de conhecimento.

Ainda sobre o jogo, Adriana Friedmann (1996, P.20).diz:

[...] acredito no jogo como uma atividade dinâmica, que se transforma de um contexto para outro, de um grupo para outro: daí a sua riqueza. Essa qualidade de transformação dos contextos das brincadeiras não pode ser ignorada".

Corroborando com essa visão, ampliando essa discussão, Celso Antunes (2008), em sua obra: "O jogo e a educação infantil”, coloca algumas diferenças importantes sobre os tipos de jogos. Assim, tem-se o jogo cooperativo, onde a criança precisará de motivação e união do grupo, para alcançar a vitória. Nesse tipo, a criança ainda tem a possibilidade de despertar a confiança, o respeito e, acima de tudo, aprender a se comportar-se em grupo. Do outro lado, o jogo competitivo que como a própria nomenclatura traz, sua essência é a competição. Esse tipo pode desencadear um possível desconforto, pois apenas haverá um ou uma equipe vencedora. Contudo, cabe ao educador mediar possíveis situações. Para tanto, ambos desenvolvem atividades em conjunto, para chegarem a um determinado objetivo que é a resolução de problemas.

Antunes (2002) completa que os jogos ou brinquedos pedagógicos são desenvolvidos com a intenção explícita de provocar uma aprendizagem significativa, estimular a construção de um novo conhecimento e principalmente, despertar o desenvolvimento de uma habilidade operatória. Nesse sentido, necessário se faz que o professor perceba que não pode 
considerar qualquer jogo como material pedagógico, já que existem jogos apenas de caráter lúdico e que não da para serem considerados como jogos pedagógicos.

No início, os jogos eram utilizados de forma secundaria, ou seja, como complemento para reforçar a aprendizagem ou ainda como prêmios para aqueles alunos que conseguiam realizar suas tarefas em tempo recorde. Segundo Kamii e Declark (1995), esses devem estabelecer relação direta com o ensino da matemática, o mesmo deve ser trazido de um plano secundário para um plano principal na aprendizagem. Onde são considerados como meios suficientes e mais eficazes para a aprendizagem dessa disciplina.

Porém, alguns professores de matemática ainda não aceitam o fato de que o ensino de matemática requer contribuições de outras áreas do conhecimento, uma vez que o fenômeno educativo é multifacetado, e com essas contribuições surgem diversas reflexões acerca de novas propostas de ensino que facilitarão a prática do professor em sala de aula e a possibilidade de se avaliar melhor os erros cometidos, em nome da melhoria do ensino da matemática.

Em suma, a criança que joga e brinca busca alegria e diversão, e ainda troca de experiências e possibilidades de aprendizagem. Ao participar da ação do brincar, o sujeito imagina e realiza os seus desejos através dos jogos, brinquedos e brincadeiras, expressando suas vontades e sentimentos

\section{CONTRIBUIÇÕES DA LUDICIDADE NO PROCESSO DE ENSINO APRENDIZAGEM}

A ludicidade, no contexto contemporâneo, ganhou uma nova roupagem e uma importância muito grande no que diz respeito ao processo de ensinoaprendizagem. Antes o que era apenas um brincar só por brincar, por puro divertimento, tornou-se um coadjuvante, um facilitador no âmbito educacional voltando ao desenvolvimento humano através das práticas pedagógicas lúdicas.

O ato de brincar, por si só, traz consigo diversas informações sobre o sujeito. Tudo é representativo, simbólico e significativo no contexto da criança (VIGOTSKY, 1991). Para conhecer a criança basta permitir-lhe que se 
expresse da maneira que ela se sinta mais a vontade e com liberdade para tal. Não se pode desconsiderar que através do lúdico o educando aprende a respeitar regras, a esperar sua vez de jogar, até mesmo criar estratégias e transportar esse aprendizado para sua vida cotidiana.

Almeida (2003) afirma que a atividade lúdica é o berço das atividades intelectuais da criança, sendo por isso, indispensável à prática educativa, pois, é através do brincar que a criança mostra sua interpretação de mundo, de suas vivências. Diante disso, pode-se dizer que, as atividades lúdicas não correspondem apenas aos brinquedos, mas dinâmicas de grupo ou individuais, brincadeiras grupais com regras estabelecidas, a utilização da música, dança, teatro, experiências de campo. São inúmeras as atividades que se pode desenvolver com as crianças para trabalhar determinado conteúdo. Segundo Queiroz (2009) a presença da ludicidade na sala de aula, em certa medida, facilita desenvolver nos educandos habilidades relacionadas aos aspectos motores, sociais, cognitivos, como também emocionais.

- qualquer recurso deve servir para que os alunos aprofundem e ampliem os significados e noções matemáticas;

- os jogos só são úteis se provocarem, em quem os utiliza, processos de reflexão sobre as noções matemáticas que se quer desenvolver a partir de seu uso;

- é importante que o jogo selecionado seja adequado aos objetivos que você traçou para seu trabalho com a Matemática;

- é fundamental que os alunos possam discutir as ideias que vão tendo e as descobertas que vão fazendo, enquanto jogam;

- ao planejar ações envolvendo jogos para a sua turma, pense com antecedência em questões a serem propostas enquanto os alunos jogam;

- é preciso prever um tempo para que, ao final do trabalho proposto, os alunos discutam e registrem suas conclusões, suas descobertas;

- um mesmo jogo deverá ser usado em momentos diferentes para desenvolver novas ideias, aprofundar aquelas já percebidas pelos alunos, ou mesmo para rever noções que não ficaram muito claras numa primeira exploração (SEEP, 2018).

Quando os alunos estão em contato com jogos e/ou outros recursos dentro da matemática não o fazem como puros assimiladores de conhecimentos, mas sim que, nesse processo, existem determinados componentes internos que não podem deixar de ser ignorados pelos professores. Nesse sentido, é preciso refletir sobre quais seriam os objetivos a serem alcançados pelos alunos, porque o jogo não pode ser tratado apenas como uma "brincadeira", pois perderia assim sua real função. Dessa forma, os 
objetivos devem estar bem claros para o professor, para que possam ser refletidos a seus alunos também de forma clara.

Kishimoto (2001), considera que o uso do jogo para auxiliar no processo de ensino-aprendizagem torna-se um instrumento relevante para 0 desenvolvimento do aluno, uma vez que potencializa a exploração e a construção do conhecimento, por contar com a motivação interna, típica do lúdico. Nesse sentido os jogos são instrumentos que auxiliam no ensino favorecendo também a aprendizagem de conteúdo, propiciando a aquisição de habilidades desde o desenvolvimento operatório da criança. Desta forma, os educadores, precisam entender e refletir sobre a importância do uso dos jogos como ferramenta facilitadora do processo de ensino aprendizagem da matemática.

O jogo como promotor da aprendizagem e do desenvolvimento passa a ser considerado nas práticas escolares como importante aliado para o ensino, já que colocar o aluno diante de situações de jogo pode ser uma boa estratégia para aproximá-lo dos conteúdos culturais a serem veiculados na escola, além de poder estar promovendo o desenvolvimento de novas estruturas cognitivas. (MOURA, 1999, p. 80)

A variedade e uso de materiais concretos para as situações pedagógicas já levou muitos a caracterizarem os jogos como brinquedos com a total função lúdica e descaracteriza-los pedagogicamente. Com isso, entende-se que o conhecimento matemático é construído pelo sujeito em interação com o ambiente físico e social, assim, deve-se reconhecer a importância dos encaminhamentos pedagógicos para possibilitar as construções pretendidas no âmbito dessa área do conhecimento escolar.

Kishimoto (1994) destaca que a utilização dos jogos como suporte ou auxilio na ação docente, em certa medida, objetiva a apreensão de conceitos e desenvolvimentos de habilidade. A autora defende a utilização dos jogos na educação escolar, porém com ressalva, desde que respeite a natureza do ato lúdico, apresentar caráter educativo e pode receber também à denominação geral de jogos educativos. Com isso seu foco é desenvolver competências.

Em outras palavras, com os jogos matemáticos proporcionam ao aluno a possibilidade de desenvolver todo o seu potencial, tomando iniciativa, planejando, exercitando e até mesmo avaliando. Ou seja, aprendendo a tomar decisões transformando o seu contexto social na matemática do faz de conta. 
Além disso, os jogos tem o poder simbólico que abre um espaço para apreensão de significados no seu contexto e apresenta as possibilidades de conquistas no seu mundo imaginário.

Com a utilização dos jogos matemáticos em sala de aula, os educandos e os educadores têm a possibilidade de explorar um determinado conceito matemático de forma lúdica. Uma vez que existe uma variedade de jogos que associados às situações problemas, se enquadram nessas características da forma lúdica para lidar com o conceito. É possível que os alunos que aprendem também com os jogos, a oportunidade de interação e o desejo de jogar da melhor maneira possível, para alcançar seus objetivos (nesse processo que pode ocorrer à competitividade).

\begin{abstract}
A criança não é atraída por algum jogo por forças externas inerentes ao jogo e sim por uma força interna, pela chama acesa de sua evolução. É por essa chama que busca no meio exterior os jogos que Ihe permitem satisfazer a necessidade imperiosa posta por seu crescimento. (ANTUNES, 2002, p.37).
\end{abstract}

Dentro dessa perspectiva, o jogador/educando busca superar obstáculos, tanto cognitivos quanto emocionais. Cabe ressaltar que se convenientemente planejados, se torna um recurso pedagógico eficaz para a construção do conhecimento matemático. Referimo-nos àqueles que implicam conhecimentos matemáticos. Para isso, as atividades com jogos não poderão ser aplicadas sem que haja um planejamento por parte do professor, uma vez que os jogos para atrair o interesse dos alunos precisam ser interessantes e desafiadores, com objetivos, metas e regras para serem alcançados.

Segundo Antunes (2002, p.40) "os jogos devem ser utilizados quando a programação possibilitar e somente quando se constituírem em um auxílio eficiente ao alcance de um objetivo dentro dessa programação." Deste modo, esses ainda se justificam e condicionam ainda o desenvolvimento de algumas habilidades como: "1. Capacidade de se constituir em um fator de autoestima do aluno; 2. condições psicológicas favoráveis; 3. condições ambientais; 4. fundamentos técnicos". Assim, os alunos se sentirão desafiados a buscarem respostas, argumentando e propondo soluções que é o objetivo do jogo, pois, alguns conteúdos matemáticos quando apresentados de forma lúdica, a matemática passa a ser vista de forma prazerosa e os alunos passam a dar 
significado ao aprendizado em sua vida.

Outro fator interessante é que o uso de jogos e curiosidades no ensino da Matemática tem o objetivo de fazer com que os alunos gostem de aprender essa disciplina, mudando a rotina da classe e despertando o interesse dos que estão envolvidos.

\begin{abstract}
Desse modo, o jogo, na Educação Matemática, passa a ter o caráter de material de ensino quando considerado promotor de aprendizagem. Criança, colocada diante de situações lúdicas, apreende a estrutura lógica da brincadeira e, deste modo, aprende também a estrutura matemática presente (MOURA, 1996, p.80).
\end{abstract}

Assim, o jogo promove o desenvolvimento, porque está impregnado de aprendizagem". Percebemos com isso, que as regras que fazem parte do jogo possibilitam uma melhor aprendizagem do assunto que está sendo estudado, abrindo caminhos para compreensão de conhecimentos futuros. Com isso, percebe-se que o aluno quando é convidado a participar de atividades lúdicas, ele aprende a estrutura lógica dessa atividade e consequentemente também aprende a estrutura matemática presente. Ainda segundo o mesmo autor,

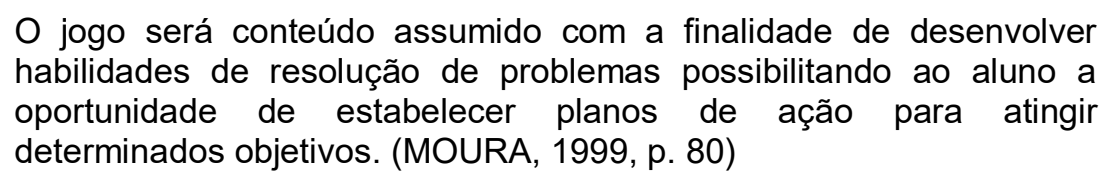

Diante dessa perspectiva, percebe-se que as habilidades que os alunos desenvolvem quando estão participando desses jogos, faz com que eles se aproximem da matemática desenvolvendo habilidades que ajudará na resolução de problemas. Uma vez que, é comum em sala de aula, ouvir dos alunos que a matemática é muito difícil, incompreensível e misteriosa, porém quando os conteúdos são trabalhados com atividades lúdicas eles aprendem que podem pensar por si mesmo e se tornam mentalmente mais ativos quando se defrontam com um oponente.

\title{
CONSIDERAÇÕES FINAIS
}

A partir do levantamento bibliográfico, pode-se evidenciar a importância da ludicidade atrelada ao ensino da Matemática para a formação do educando. Os jogos, os brinquedos e as brincadeiras, quando trabalhados de forma planejada, organizada, atentando-se às problemáticas dos estudantes, a 
utilização do lúdico pode proporcionar momentos de ensino e aprendizagem significativos para seu desenvolvimento, além de oportunizar situações em que se possa melhorar, aprender e vislumbrar um futuro promissor.

No âmbito das atividades com jogos e brinquedos com caráter pedagógico, é importante que os alunos participem de todo o processo desde a construção até a aplicação em sala de aula, de forma que esse aluno o educando se sinta instigado a buscar soluções, contextualizando teoria e prática, para que o conhecimento específico do conteúdo da disciplina não se separe da prática. Pois, quanto mais o aluno manipula o material, seja na construção das peças do jogo até a execução da atividade, mais possibilidades de compreensão eles terão, uma vez que cada jogo e/ou brincadeira são estruturados em torno de regras de apresentações simbólicas.

Os jogos em grupo, por exemplo, podem ajudar os alunos a pensar, comparar e debater sobre os assuntos envolvidos. Pois, as atividades lúdicas no ensino da matemática são mais desafiadoras do que a mera representação dos livros didáticos e dos exercícios tradicionais. Nas práticas que envolvem a ludicidade, os educandos estabelecem suas próprias razões, regras e caminhos para a resolução de "problemas" que essas situações evocam. Assim, os jogos vêm assumindo um papel bastante importante no processo de ensino aprendizagem da Matemática

Diante dessa perspectiva, muitas são as contribuições das atividades lúdicas nesse processo, para isso, elas devem ser bem planejados, para que haja um sentido e para que o aluno possa sempre fazer um link e dar um significado, ligando a atividade com objeto em estudo. Portanto, essas podem e devem ser utilizados para introduzir, amadurecer conteúdos e preparar o aluno para aprofundar os itens já trabalhados. Porém, necessário se faz ter cautela na escolha desses materiais e/ou metodologia para aplicá-los.

Portanto, é preciso compreender que a ludicidade pode contribuir de maneira efetiva no desenvolvimento e no despertar de habilidades e competências necessárias, não apenas na Matemática, mas em qualquer área do conhecimento.

\section{REFERÊNCIAS}


AFONSO, P. B. Vencendo as armadilhas da educação matemática por meio da abordagem etnomatemática, 2002. Disponível em: Acesso em: 29 março 2013

ALMEIDA, P. N. Atividade Lúdica: técnicas e jogos pedagógicos. São Paulo, SP: Loyola, 2003.

ANTUNES, C. Como desenvolver conteúdos explorando as inteligências múltiplas. Petrópolis, RJ: Vozes, 2002.

ARANÃO, I. V. D. A Matemática através de brincadeiras e jogos. Campinas, SP: Papirus, 1996.

BRASIL. [Lei Darcy Ribeiro (1996)]. LDB: Lei de Diretrizes e Bases da Educação Nacional [recurso eletrônico] : Lei $n^{\circ}$ 9.394, de 20 de dezembro de 1996.

BRASIL. Parâmetros Curriculares Nacionais: Matemática. Brasília DF: MEC, 1997.

BOUGÈRE, G. Brinquedo e Cultura; versão técnica e versão brasieira adaptada por Gisela Wajskop. Cortez, São Paulo, 2001.

BRITO, M. D. C. A História da Matemática no Brasil. 2007. Trabalho de conclusão de Curso. (Graduação em Licenciatura em Matemática) Universidade Católica de Brasília.

BRITO, A. J.; CARVALHO, D. L. Utilizando a história no ensino de Geometria. In: MIGUEL, Antônio. et al. História da Matemática em Atividades Didáticas. 2. ed. São Paulo: Livraria da Física, 2009.

CREPALDI, M. A. S. A História da matemática na apropriação dos conteúdos da $6^{a}$ série do ensino fundamental. UNESC, 2005.

FRIEDMANN, A. Brincar, crescer e aprender - O resgate do jogo infantil. São Paulo: Moderna, 1996.

GRANDO, R. C. 0 jogo e suas possibilidades metodológicas no processo ensino-aprendizagem da matemática. Dissertação de Mestrado. Campinas: Unicamp, 1995.

GIL, A. C. Como elaborar projetos de pesquisa. São Paulo: Atlas, 2010a HUIZINGA, J. Homo Ludens: $O$ jogo como elemento da cultura . São Paulo: Perspectiva, 2005.

JESUS, A. C. A. J. Como aplicar jogos e brincadeiras na educação infantil. Brasporte. São Paulo. 2010

KISHIMOTO, T. M. O jogo e a Educação Infantil. 2. Ed. São Paulo: Pioneira, 
1998.

KISHIMOTO, T. M. Jogo, Brinquedo, Brincadeira e a Educação. $3^{\circ}$ ed. São Paulo - Editora Cortez. 1999,MG: Autêntica, 2008.

LAKATOS, E. M.; MARCONI, M. A. Fundamentos metodologia científica. 4.ed. São Paulo: Atlas, 2001.

LAVORSKI, J. I; VENDITTI JUNIOR, R. V. A ludicidade no desenvolvimento e aprendizado da criança na escola: reflexões sobre a Educação Física, jogo e inteligências múltiplas. Revista Digital .Buenos Aires - Año 13 - No 119 - Abril de 2008. Disponível em: <http://www.efdeportes.com/> Acesso em 10 de janeiro de 2019.

LUCKESI, C. C. Desenvolvimento dos estados de consciência e ludicidade. Data de publicação no site: 21.11.2005. Disponível em:<http://www.luckesi.com.br/artigoseducacaoludicidade.htm>. Acesso em: 11 de fevereiro de 2018.

MIGUEL, A.; MIORIM, M. A. História na educação matemática: propostas e desafios. 2. Ed., Belo Horizonte/MG: Autêntica, 2011.

MOURA, M.O. de. A construção do signo numérico em situação de ensino. São Paulo:USP,1996.

MINAYO, Maria Cecília de Souza. (Org.). Pesquisa social: teoria, método e criatividade. Petrópolis: Vozes, 2001.

PENTEADO, H. D. Jogo e formação de professores: videopsicodrama pedagógico. In: KISHIMOTO, M. T. et al. (Org.) Jogo, brinquedo, brincadeira e a educação. 3. ed. São Paulo: Cortez, 1999.

PIAGET, J. Aprendizagem e conhecimento. Rio de Janeiro: Freitas Bastos, 1973.

QUEIROZ, E. M. Teoria da Aprendizagem. UNINOVE (Universidade Nove de Julho).

Disponível em:<file:///C:/Users/cliente1/Desktop/Nuvem\%20MEGA/LIVROS,\%20ARTIGOS ,\%20CITAÇÕES/Teorias\%20da\%20Aprendizagem.pdf> Acesso em: 11 de fevereiro de 2018.

SANT'ANNA, A.; NASCIMENTO, P. R. A história do lúdico na educação. Revista Revemat. Florianópolis (SC), v. 06, n. 2, p. 19-36, 2011.

VERGARA, S. C. Métodos de coleta de dados no campo. São Paulo: Atlas, 2009.

VYGOTSKY, L.S. A formação social da mente. São Paulo: Martins Fontes, 1991 